\title{
Investigation of Trafficking: Establishing the Circumstances Subject to a Proof
}

\author{
Boretsky Alexey Vladimirovich ${ }^{1}$, Djorobekova Arzigul Mamajunusovna ${ }^{2} \&$ Pen Sergey Gennadjevich ${ }^{3}$ \\ ${ }^{1}$ Innovative University of Eurasia, Pavlodar, Kazakhstan \\ ${ }^{2}$ Academy of the MIA of the Kyrgyz republic after E.A. Aliyev, Bishkek, Kyrgyzstan \\ ${ }^{3}$ Kazakh Humanitarian Law University, Astana, Kazakhstan \\ Correspondence: Boretsky Alexey Vladimirovich, Innovative University of Eurasia, 140000, Pavlodar, M. Gorky, \\ St., 102/4, Kazakhstan. Tel: 7-701-492-8667. E-mail: alexey1977.77@mail.ru
}

Received: April 21, 2015 Accepted: April 28, 2015 Online Published: July 1, 2015

doi:10.5539/jsd.v8n6p111 URL: http://dx.doi.org/10.5539/jsd.v8n6p111

\begin{abstract}
The purpose of this work is to investigate the circumstances subject to a proof in criminal cases on human trafficking, in order to ensure the effective investigation of criminal cases in this category. The authors propose to classify the circumstances subject to a proof, depending on the elements of offense, based on the analysis of criminal and criminal procedural legislation of the Republic of Kazakhstan and the Kyrgyz Republic, as well as investigation practice of the criminal cases on trafficking in persons. The use of the classification of the circumstances, subject to a proof, submitted by the authors, in the investigation of trafficking in human beings, by the law-enforcement authorities, allows ensuring the comprehensiveness, completeness and impartiality of the investigation and improves the quality of the investigation of such crimes.
\end{abstract}

Keywords: human trafficking, investigation of criminal cases, circumstances to a proof, the offense, exploitation of people

\section{Introduction}

The transition of the post-Soviet states to the market economy, accompanied with the economic crisis, had a negative impact in the ideological and moral, social, political and other spheres of society and aggravated the crime situation in the former Soviet Union (USSR) as a whole and both Kazakhstan and Kyrgyzstan in particular. The law enforcement authorities of the Republic of Kazakhstan (RK) and the Kyrgyz Republic (KR) note the intensification of organized crime formed by various criminal groups, which are aimed at the legally protected rights and interests of citizens. In this regard, the issues of improving the efficiency of combating the crimes against a person, including human trafficking are relevant in the modern period.

An analysis of the Ministry of Interior Affairs of the Republic of Kazakhstan (MIA RK) and the Ministry of Interior Affairs of the Kyrgyz Republic (MIA KR) investigative practices shows that an enquiry of trafficking in both countries is related to a number of serious challenges. Which include: undeveloped legal framework, lack of interagency cooperation at the national and international levels, inadequate funding for law enforcement agencies to combat human trafficking, and the lack of scientific research aimed at improving the effectiveness of the fight against these crimes. There is also noted the vicious practice of creating favorable statistics, when the law enforcement officials act to the detriment of the investigation quality in order to ensure the quantitative indicators. In this connection, the review of the Investigative committee of the MIA RK "On the status of investigation of criminal cases related to human trafficking by internal affairs agencies for 2010-2012", emphasized that the quality of investigation of criminal cases on human trafficking is unsatisfactory, as it allows unnecessary termination and suspension of criminal cases in this category (Review of the Investigative Committee of the MIA RK "On the status of investigation of criminal cases related to human trafficking by internal affairs agencies for 2010-2012", 2013).

In addition, it should be noted that during the investigation of human trafficking, the investigators and operatives of the MIA RK and the MIA KR meet difficulties in determining the circumstances, subject to a proof, which inevitably affects the quality and results of the investigation of these criminal cases.

Problems of counteraction and investigation of human trafficking have been reflected in the works of such 
authors as Laczko (2005), Cho et al. (2014), Gozdziak and Collet (2005), Limoncelli (2009), Boretsky and Zhetpisov (2013), Shelley (2010) and Stoecker (2010), but unfortunately, the circumstances to a proof were not considered at all or not adequately considered in these studies.

As far back as Roman lawyers associated ascertainment of the truth in any criminal case with the response to so-called seven-term formula: what, where, when, how, who, with the help of whom, why? (Criminalistics textbook, 1959).

Criminal procedure legislation of the Republic of Kazakhstan (The Code of Criminal Procedure of the Republic of Kazakhstan, 2014) and the Kyrgyz Republic (The Code of Criminal Procedure of the Kyrgyz Republic, 1999) define the subject of a proof in detail. For example, Article 113 Code of Criminal Procedure RK and Article 82 Code of Criminal Procedure KR state that during the initial inquiry, the preliminary investigation and criminal proceedings in court, the following issues must be proved:

- an event and signs of a criminal offense stipulated by criminal law (time, place, method and other circumstances of the offense);

- who has committed an act prohibited by criminal law;

- the guilt of the person in committing an offence prohibited by criminal law, the shape of his guilt, the motives of the offense, the legal and factual errors;

- the circumstances, affecting the degree and nature of the liability of the suspect and the accused;

- the circumstances that characterize the identity of the suspect, accused;

- the consequences of a criminal offense;

- the nature and extent of the harm, caused by a criminal offense;

- the circumstances, precluding the criminal wrongfulness of a deed;

- the circumstances leading to exemption from criminal liability and punishment.

In addition, these rules of the criminal procedure require identifying the causes and conditions conducive to committing the crime.

The criminal procedure legislation of the Republic of Kazakhstan and the Kyrgyz Republic determine the general concept of the subject of a proof, so it should be noted that each item of Article 113 Code of Criminal Procedure RK and Article 82 Code of Criminal Procedure KR comprises a certain group of factual circumstances, covering in total one of the issues to be addressed in the case and of possible significance for understanding of other issues. It is impossible to disclose the content of the subject of a proof without the criminal legal regulations (Kocharov et al., 1966), however, despite the importance of the legal regulations, they also do not cover all the contents of the subject of a proof. For example, in cases of human trafficking such things as methods of recruitment, displacement, exploitation of the victims and the circumstances contributing to the commission of a crime, do not apply to the composition of human trafficking, but should be referred to the subject of a proof in the case of trafficking in human beings.

Thereby, the aim of the present study is determination of the circumstances, subject to be proved, in the investigation of human trafficking, for the purpose of ensuring the comprehensiveness, completeness and impartiality of investigation of the criminal case sand improving the quality of the investigation in the Republic of Kazakhstan and the Kyrgyz Republic.

\section{Research Methods}

In the methodological basis of the study lies the system of common, separate and special methodological principles, approaches and methods of scientific cognition, applicable either separately or in combination with each other. In particular, there have been used such methods as dialectical, historical, comparative analysis, simulation, statistical and systematic-structural, action and situational approaches to the study of the processes and phenomena.

In addition, the study used sociological techniques such as questionnaires and interviews with the victims, law enforcement officials and representatives of the crisis centers.

In the course of the present study, there was made an analysis of the criminal cases of human trafficking, considered in the courts and being under criminal proceedings, with the purpose of exposure of the investigation deficiencies and errors, committed by the investigation subjects.

In order to achieve the objective results of the study these methods were applied comprehensively. 


\section{Results and Discussion}

\subsection{The Circumstances to be Proved in the Cases of Trafficking in Human Beings and Their Classification}

The issue of the correlation between the subject to be proved and the criminal characteristics largely depends on how to understand the subject of a proof, «circumstances to be proved» and criminalistic characteristics of a crime. Drapkin (1978) expressed an original opinion, pointing that as we move from a higher level of community to lower, the circumstance in proof includes a growing number of evidentiary facts, it becomes more and more detailed, and finally turns into «a new set of circumstances, to comply fully with evidentiary and search functions». The aggregate of the evidence on this combination of circumstances compiles the criminalistic characteristics of an individual sort (group) of crimes (Drapkin, 1978).

A specific crime and the related circumstances that require clarification, represent a set of facts that occur in the reality. These facts are always concrete, so the subject of proof in a particular case is individual. At the same time, each of the mentioned in the legislation «circumstances» is normally expressed not in a particular fact, but in their series. Therefore, a large number of different facts in a particular case is generally subject to ascertainment.

However, not all the facts, established in a particular criminal case by the use of evidence, compose the subject of proof. Often, in proving, there is a need to establish a number of such subsidiary, adverse facts, which are not included in the circumstances to be proved in a criminal case; they have no criminal legal effect and serve as means to establish the facts, constituting the subject of proof in the case. Such facts are usually intermediates in the course of establishing the circumstances of the subject. In addition, virtually every criminal case, depending on the stage of investigation and specific investigative situation, faces the task to establish certain facts that are relevant to the case, but not included in the subject of proof. Therefore, if we refer supporting facts to the circumstances, subject to be proved in a criminal case, it may lead to such expansion of these circumstances, that it would complicate the practical use of private criminalistic investigation techniques in various types of crime.

In the works on criminalistics, while determining the subject of a proof, it is recommended to guide the process of investigation by not seven- or twelve-part formula but questions grouped in separate elements of the offense (Fatkullin, 1976).

Thus, we believe that this element of criminalistic characteristics should be specified in terms of the essential facts, subject to a proof in a criminal case, grouped according to the elements of the crime of human trafficking:

- the basic circumstances relating to the object of encroachment (the direction of the assault, what is damaged, its size, etc.).

- the basic circumstances relating to the actus reus of the infringement (where, when, how, by the actions of one or several persons, the role of each, under what circumstances, what are the consequences, damages, causal link between the act and the consequences, the circumstances that contributed to the crime, etc.);

- the basic circumstances relating to the subject of offence (who committed the infringement; data describing his personality, if a group of people is involved, who are they, what is the role of each of them, and so on);

- the basic circumstances relating to the mental element of encroachment (guilt, its shape, the motive and purpose - with intentional guilt).

In our opinion, this point of view is the most appropriate because it allows a consistent analysis of the specificity of the full range of circumstances to be clarified in the investigation of such crimes, and at the same time provides a relatively simple practical application. When investigating the cases on trafficking, the most appropriate is to group the main circumstances to be proved by individual elements of the crime.

\subsection{The Main Circumstances Relating to the Object of the Crime}

Any crime encroaches on a certain object, causing it significant damage. Human trafficking is a crime against the freedom of an individual; therefore the direct object of trafficking is personal freedom (Mizulina, 2006).

The crime in question may cause an irreparable damage. Therefore, from the standpoint of the circumstances, subject to a proof, it is necessary to prove the damage caused is a result of human trafficking. Besides proving the damage to the object of offense, in criminal cases involving human trafficking it is required to establish the victim of the damage, since this circumstance greatly affects the course of investigation of the considered criminal acts, the lack of a victim in a particular criminal case would inevitably lead to further problems in proving the guilt of the persons who committed a crime. However, it is necessary to establish the number of victims of this crime, as failure to identify at least one of the victims would entail violation of Article 24 Code of Criminal Procedure RK and Article 19 Code of Criminal Procedure KR on comprehensiveness, completeness 
and objectivity of the investigation of the criminal case.

A peculiarity of human trafficking is that it may lead to the victim's health hazard, which in turn significantly affects the additional qualification of a criminal act. Furthermore, the investigator must prove whether the harm (moral, material, physical) was caused to other persons besides the direct victim, which in turn also plays an important role in the investigation of these crimes. Along with the above mentioned circumstances, in every criminal case there must be carefully ascertained the gender, age of the victim, occupation and other features of their importance, as well as the extent of criminal activity on human trafficking.

Thus, the main circumstances to be clarified and related to the object of the crime, will include the questions:

- Who is a victim of trafficking;

- Was the offense committed against one or more persons;

- What is the age and sex of the victim;

- What damage have been caused by the crime;

- Who suffered the damage from the crime except for the victims;

- Whether the health of the victim was harmed and the extent of its severity;

- What is the scope of criminal activities on human trafficking.

\subsection{The Main Circumstances Relating to the Actus Reus}

Analysis of Article 113 Code of Criminal Procedure RK and Article 82 Code of Criminal Procedure KR indicates that the legislators of both countries put the elucidation of the crime occurrence in the first place, that is, the time, place, method and other circumstances of the crime. Therefore, in the investigation of trafficking cases there must be proven not only the fact of the sale or other transactions in respect of a person, exploitation, recruitment, transportation, transfer, harboring, and committing other acts for the purpose of exploitation, but also clarification of other objective evidence of the crime - when, where, how and under what circumstances was committed the crime of human trafficking.

According to Part 1, Article 128 of the Criminal Code RK (CC RK) and Part 1, Article 124 of the Criminal Code $\mathrm{KR}$ (CC KR), the modus operandi of the human trafficking is the sale or other transactions in respect of a person, as well as its exploitation or recruitment, transportation, transfer, harboring, and committing other acts for the purpose of exploitation. In this regard, during the investigation of human trafficking it must be discovered in what location (in Kazakhstan, Kyrgyzstan or outside their borders) and under what circumstances were committed such actions.

The time of perpetration of human trafficking is also a subject to clarification that is included in the concept of the crime. The subject to a proof is a particular specified period of time when the crime was committed, that is, the specific time of all actions, specified in Part 1 Article 128 of the CC RK and Part 1, Article 124 of the CC $\mathrm{KR}$. The method of committing human trafficking is the obligatory indication of the actus reus of the crime that is required to be proved.

Trafficking in human beings, in our opinion, can be accomplished in four main ways, depending on the alleged location of the victim's exploitation and crossing the border of Kazakhstan, if it:

- is related to the transportation of people from the RK for subsequent sale or use on the territory of another state;

- is associated with the import of people on the territory of Kazakhstan for sale and exploitation within its territory;

- entails transit of people from one country to another through the territory of the Republic of Kazakhstan;

- takes place entirely in the territory of the Republic of Kazakhstan.

In addition to these, there also can be classified other methods of committing the crime for other reasons, for example, depending on the nature of the actions of the perpetrator. The legislators of Kazakhstan and Kyrgyzstan cite this differentiation in Part 1, Article 128 of the Criminal Code RK and Part 1, Article 124 of the Criminal Code KR.

To such methods the law attributes human trafficking, committed by: Purchase and sale; Other transactions; Exploitation; Recruitment; Transportation; Transfer; Concealment; Committing other deeds for the purpose of exploitation. The above mentioned ways of trafficking are optional, specifying or defining in relation to the main or general method of committing the crime - trafficking in human beings; they define the specific unlawful 
nature of the general modus operandi. Thus, the presence of the general modus operandi is the subject to be proved in the cases of human trafficking along with one of the compulsory alternative optional methods.

In proving these basic facts relevant to the actus reus of the crime, it should be noted that the actions, associated with the crossing of the state border of the Republic of Kazakhstan and the Kyrgyz Republic and mentioned in Part 1, Article 128 Criminal Code RK and Part 1, Article 124 Criminal Code KR, might be performed:

- using the original documents of the victims;

- using forged documents of victims, specially made for this purpose;

- bypassing the official border and customs posts of the RK and the KR.

Moreover, the victims can be transported by a criminal or a member of a criminal group or cross the border on their own without support. In the case of using false documents it is essential to figure out the way of acquiring the documents intended to cover the trafficking at border crossing, and to identify the persons involved in it. The fact of smuggling the victims of trafficking across the border without accompanying persons at the time of crossing the border is not easy to detect, but it is even more difficult to prove the fact of committing the crime by a specific person.

The main facts relevant to the actus reus of the assault, are:

- Where were committed the criminal acts (in the territory of the Republic of Kazakhstan or abroad);

- At what particular time was accomplished the trafficking;

- In what way the victim was exploited;

- What methods were used to conceal the crime of human trafficking;

- What are the methods of recruiting the victims;

- At what stage was prevented the committing of the offense;

- Whether there are circumstances excluding criminal responsibility.

\subsection{The Main Circumstances Related to the Offender}

Currently the persons engaged in human trafficking are citizens of the Republic of Kazakhstan and the Kyrgyz Republic, individual foreign citizens, arriving into the country on private business, as well as former citizens who went abroad for permanent residence. Trafficking in persons is often committed by a group of persons by prior agreement. In this case, the criminal role of each member of the group is determined in advance: one recruits the victims, others - transfer the victims, the third - transport, the fourth - exploit, the fifth - buy and exploit. An organized stable group of traffickers is difficult to expose. Due to increased social danger of the act committed by an organized group, the law allocates committing of the considered acts by a group of people, especially organized for this purpose, as one of the aggravating circumstances of trafficking. At the same time, the subject of this crime can be both the citizens of the Republic of Kazakhstan and the Kyrgyz Republic, as well as foreigners and stateless persons. An important task of the subject of the investigation is to identify all the members of the criminal group.

Thereby, the total of the circumstances subject to a proof, related to the subject of trafficking in human beings, as follows:

- Whether the trafficking was committed by one person or a group of persons;

- Whether there has been a prior agreement, the distribution of roles in the group for the perpetration of the criminal act;

- What the role of each partner was;

- What are the structure, the degree of stability and direction of the group;

- Whether there is a foreign citizen in the group;

- The personal data of all members of the group (age, profession, occupation, responsibility, place of residence);

- Whether the persons have had committed such crimes before and were convicted in the past.

\subsection{The Main Circumstances Related to the Mental Element in the Crime}

A correct and complete establishment of the facts constituting the actus reus of the act is an indispensable condition for the proper resolution of the case. Without the proof of these facts, it is impossible to resolve the 
question of the guilt of the accused and to qualify the deed properly.

The legislation specifies only the form of intent, among the essential characteristics of the mental element in human trafficking, and only the direct intent, when a person is aware of the social danger of his actions and wants to accomplish them. Therefore, in the first place, it is necessary to establish the content of intent, whether it covers all the actual signs of past events, which form the elements of human trafficking.

The investigator must keep in mind, that for the proper investigation and qualification of the offense, it is very important to ascertain the direction of intent, because it is the precise distinctive feature of human trafficking, versus kidnapping (Article $125 \mathrm{CC}$ RK and Article $123 \mathrm{CC} \mathrm{KR}$ ), illegal deprivation of liberty (Article $126 \mathrm{CC}$ RK and Article $125 \mathrm{CC} \mathrm{KR}$ ), the forced withdrawal or the unlawful removal of human organs and tissues (Article 116 of the Criminal Code CC RK and Article 114 CC KR) in particular.

The features characterizing the mental element of human trafficking include the motive and purpose of committing the crime. Despite the fact that the purpose and motive are not compulsory mental elements of human trafficking, as they are irrelevant for qualification of the traders' actions, in accordance with the requirements of the procedural law both the motive, and the purpose are always included in the scope of proof. The motive must be established in each case, as without this it is impossible to properly address the question of the degree of social danger of the crime, and, consequently, on the individualization of punishment.

Thus, the basic circumstances, relating to the mental element of the offense to be proved, as follows:

- Whether the perpetrator was aware of the public danger of trafficking;

- Whether he wished to commit a crime of the category considered;

- What pushed him to commit trafficking in persons;

- What goal was he pursuing;

- What was comprised by the intent of each partner;

- What were the motives and purposes of each partner.

The subject of a proof in the case also includes the circumstances affecting the degree and nature of responsibility of the accused (Articles 53, $54 \mathrm{CC} \mathrm{RK}$ and Articles 54,55 CC KR), as well as the causes and conditions that contributed to the commission of human trafficking. Therefore, the circumstances mitigating and aggravating the punishment of the accused (defendants) should be clarified simultaneously.

The circumstances mitigating the punishment for human trafficking include: a crime under the influence of threat, coercion, or material, service or other dependence; due to a confluence of difficult personal or family circumstances; the presence of minor children at the accused. Additional extenuating circumstances are a sincere repentance or voluntary surrender, as well as active contribution to solving the crime and the liberation of the victims of trafficking, recruited, sold or exported abroad before. It is essential to identify other circumstances of this sort, which can be recognized as mitigating by the court.

The aggravating circumstances are recognized as follows: the committing of trafficking by a person previously convicted of any crime, particularly of trafficking in persons; commission of a crime in a group of individuals, group of persons by prior conspiracy, an organized group or a criminal community; a particularly active role in the perpetration of a crime; commission of a crime with the use of physical or mental coercion.

While exploring these issues, it is necessary to identify the circumstances that characterize the identity of the accused (defendants): overall development; experience; attitude to public responsibility before committing a crime; the reasons which led to a crime and others. The establishment of the above factors can fully provide the comprehensiveness, completeness and objectiveness of the investigation of human trafficking required by law. Despite the rather intensive development of the doctrine of criminalistic characteristics of crime, its role and place in the methodology of investigation, in the recent years, there still are relevant questions about the correlation of criminalistic characteristics and the subject of proof as structural elements of the private investigation techniques and the role of information about the circumstances, subject to a proof during the investigation of certain types of crimes in criminalistic techniques.

The relationship between these concepts becomes even more relevant when there is a tendency towards convergence and even the unification of these concepts in criminalistic literature. In addition to the conventional opinion, that the determination of the circumstances, subject to a proof, is a component of private methods, there is often expressed the view that the criminalistic characterization supposedly absorbs the subject of a proof.

In particular, Belkin (1979) argued that the content of criminalistic characteristics should cover all the elements 
of the subject of a proof with those of their features that are specific to a particular category of crime investigation (Belkin, 1979).

Churilov (1980) has had taken a similar position and pointed out, that «criminalistic characterization of crimes will perform its proper role only if it reflects all the elements of the model subject of a proof in this category of crime» (Churilov, 1980).

The determination of the place of circumstances to be proved in the investigation of certain types of crimes, was and still remains a debatable issue, because the subject of a proof as a structural element of a specific private technique was previously stated after the description of features of the legal proceedings institution, and all that now belongs to the criminalistic characteristics of crimes was disclosed in the particular circumstances to be proven. For instance, some criminalists refer the circumstances, subject to be proved to the elements of criminalistic characteristics of certain types of crimes, while others place this element separately, after the criminalistic characteristics of a crime and before the typical investigative situations.

The comparison of the two points of view allowed Vozgrin (1993) to claim that each type of crime has its own particular subject of a proof and they play an important role in determining the direction and the program of the investigation (Vozgrin, 1993). Consequently, the circumstances to be proved in the investigation of certain types of crimes are of the same value as the other elements of criminalistic characteristics of crime for the private criminalistic techniques, and there is no reason to tear them apart. In addition, the structure of the private methods of investigation has no other place to describe the features of the subject of a proof than their criminalistic characteristics.

This work on the methodology of the investigation of trafficking validates the accuracy of the position, expressed above, because such elements of the criminalistic characteristics of human trafficking as the means, subject, situation and others are closely related to the basic facts to be proved, and, tearing them, we would repeat ourselves, so unnecessarily complicating the use of private criminalistic techniques in practice.

\section{Conclusions}

Thus, summarizing the results of this work, it can be argued that the circumstances requiring an ascertainment, should be presented in the form of the main circumstances, subject to a proof in a criminal case, grouped according to the elements of the corpus delicti of human trafficking:

- the basic circumstances relating to the object of offence (what is the assault directed at, what was the aim of the damage, its size, etc.).

- the basic circumstances relating to the actus reus of the infringement (where, when, how, by the actions of one person or several persons, the role of each co-executor, under which circumstances, what are the consequences, damages, causal link between the act and the result, the factors that contributed to the crime, etc.);

- the basic circumstances relating to the subject of offence (who committed the infringement; data describing his personality, if a group of people is involved, who are they and what is the role of each of them, and so on);

- the basic circumstances relating to the mental element of encroachment (guilt, its shape, the motive and purpose - with deliberate fault).

\section{References}

Belkin, R. S. (1979). Soviet criminalistics course. Part 3. Publishing House of the Academy of Ministry of Internal Affairs of the USSR, Moscow, USSR.

Boretsky, A. V., \& Zhetpisov, S. K. (2013). Human trafficking: Issues of investigation techniques. World Applied Sciences Journal, 23(1), 13-17.

Cho, S. Y., Dreher, A., \& Neumayer, E. (2014). Determinants of anti-trafficking policies: Evidence from a new index. Scandinavian Journal of Economics, 116, 429-454.

Churilov, S. N. (1980). On the principles of development and construction of private criminalistic techniques. In Problems of the preliminary investigation: Collection of scientific works (Vol. 10). Volgograd, USSR.

Criminalistics Textbook. (1959). Golunsky S.A. (Ed.). Juridicheskaya literatura, Moscow, USSR.

Drapkin, L. Y. (1978). Subject of a proof and criminalistic characteristics of crimes. In Criminalistic characteristics in the method of investigation of crimes: Collection of scientific works (Vol. 69). Sverdlovsk Law Institute, Sverdlovsk, USSR.

Fatkullin, F. N. (1976). Common Problems of Procedural Proving. Publishing House of Kazan University, 


\section{Kazan, USSR.}

Gozdziak, E. M., \& Collet, E. A. (2005). Research on human trafficking in North America: A review of literature. International Migration, 43(1-2), 99-128. http://dx.doi.org/10.1111/j.0020-7985.2005.00314.x

Kocharov, G. I., Belkin, R. S., \& Winberg, A. I. (1966). Proof Theory in the Soviet Criminal Proceedings. Juridicheskaya Literatura, Moscow, USSR.

Laczko, F. (2005). Data and research on human trafficking. International Migration, 43(1-2), 5-16. http://dx.doi.org/10.1111/j.0020-7985.2005.00309.x

Limoncelli, S. A. (2009). Human trafficking: Globalization, exploitation and transnational sociology. Sociology Compass, 3(1), 72-91. http://dx.doi.org/10.1111/j.1751-9020.2008.00178.x

Mizulina, E. B. (2006). Human Trafficking and Slavery in Russia: The International Legal Aspect. Jurist, Moscow, Russia.

Review of the Investigative Committee of the MIA RK "On the status of investigation of criminal cases related to human trafficking by internal affairs agencies for 2010-2012". (2013). Department of Internal Affairs of Pavlodar region, Pavlodar, Kazakhstan.

Shelley, L. I. (2010). Human Trafficking: A Global Perspective. Cambridge University Press, Cambridge, UK. http://dx.doi.org/10.1017/cbo9780511760433

Stoecker, S. W., \& Shelley, L. (2010). Human Traffic and Transnational Crime: Eurasian and American Perspectives. Rowman and Littlefield Publishers, Inc., Maryland, USA.

The Code of Criminal Procedure of the Kyrgyz Republic. Law of the Kyrgyz Republic. June 30, 1999. No 62. Retrieved from http://online.adviser.kg/Document/?doc_id=30241915

The Code of Criminal Procedure of the Republic of Kazakhstan. Law of the Republic of Kazakhstan. July 4, 2014. No 231-V. Retrieved from http://online.zakon.kz/Document/?doc_id $=31575852 \#$ sub_id $=6740000$

Vozgrin, I. A. (1993). Scientific fundamentals of criminalistic techniques in crimes investigation. Lectures. Part 3. Publishing House of St. Petersburg juridical institution MIA Russia Saint Petersburg, Russia.

\section{Copyrights}

Copyright for this article is retained by the author(s), with first publication rights granted to the journal.

This is an open-access article distributed under the terms and conditions of the Creative Commons Attribution license (http://creativecommons.org/licenses/by/3.0/). 